EGU21-12265

https://doi.org/10.5194/egusphere-egu21-12265

EGU General Assembly 2021

(c) Author(s) 2022. This work is distributed under

the Creative Commons Attribution 4.0 License.

\title{
Polygonal frost patterned ground as a Mars analogue in Northern Victoria Land, Antarctica
}

\author{
Cynthia Sassenroth ${ }^{1}$, Ernst Hauber ${ }^{2}$, Carlo Baroni ${ }^{1}$, Maria Cristina Salvatore ${ }^{1}$, Jean-Pierre De \\ Vera ${ }^{1}$, and Nicole Schmitz ${ }^{1}$ \\ ${ }^{1}$ Università di Pisa, Pisa, Italy (cynthia.sassenroth@phd.unipi.it) \\ ${ }^{2}$ DLR, Institute of Planetary Research, Berlin, Germany
}

Polygonal patterned ground is ubiquitous in the martian mid-latitudes and in the polar regions of Earth. The latitude dependence of martian patterned ground and its morphological similarity to terrestrial patterned ground suggests that thermal contraction cracking may have been the leading formation mechanism for those polygons. Due to a lack of ground truthing on martian patterned ground, the role of liquid water in its formation and weather freeze-thaw processes lead to their origin is still debated. This study uses a quantitative approach, based on geomorphometrical and soil characteristics of patterned ground in continental Antarctica and glacial deposits with low inclination of Terra Nova Bay as terrestrial analogues, to understand polygon formation in martian hyper-arid conditions. We investigated polygons in ice-free parts of the mountain range of Helliwell Hills $\left(\sim 71^{\circ} 43 \mathrm{~S} / 161^{\circ} 2 \mathrm{E}\right)$ in continental Antarctica and the Northern Foothills in the coastal Terra Nova Bay area $\left(74^{\circ} 45 \mathrm{~S} / 164^{\circ} \mathrm{E}\right)$.

Field observations were made during the austral summer on the GANOVEX XI and GANOVEX XIII expeditions in Dec-Jan 2015/2016 and Oct-Nov 2018, respectively. The polygonal troughs have been mapped and digitized in ArcGIS based on high resolution satellite images. For Helliwell Hills we used World View 2 images with a pixel size of $50 \mathrm{~cm}$. For Terra Nova Bay, Quickbird satellite imagery has been used with a pixel size of $60 \mathrm{~cm}$. Based on these datasets, parameters such as area, perimeter, length, and width have been measured, and size, circularity, orientation, and aspect ratio of each polygon were derived from these measurements. Additionally, we used a DTM derived from World View 2 stereo imagery (ground sampling distance: $8 \mathrm{~m}$ ) to calculate the average slope, aspect, and solar irradiation of each polygon. The quantitative analysis shows that the geomorphometric characteristics of polygons in the Helliwell Hills differ significantly from those in Terra Nova Bay. Polygons in the Helliwell Hills are significantly smaller than in Terra Nova Bay and are organized as orthogonal, random-orthogonal and hexagonal polygon networks, while all polygons in Terra Nova Bay form hexagonal polygon-net geometries. The correlation of polygonnet geometries and the slope gradient shows that hexagonal polygon-net geometries dominate in flat terrains, while orthogonal geometries have developed on steeper slopes or in the immediate proximity of sharp terrain margins such as topographic slopes. The polygons in Helliwell Hills do not display significant local relief, but overall, the polygon centres are slightly higher than the bounding cracks (i.e. high-centered polygons). In Terra Nova Bay the appearance of high centred 
polygons and a deeper trough is even more developed and well distinguishable on satellite images.

During the fieldwork in Helliwell Hills, excavations were made in the center of polygons and across the bounding cracks. Typically, the uppermost $\square 40 \mathrm{~cm}$ of regolith are dry and unconsolidated. Below that, there is commonly a sharp transition to ice-cemented material or very clear ice with no bubbles. The grain size analysis indicated no significant trend of sorting. We will present the results of our analysis and compare them with selected polygon sites on Mars. 